Article

\title{
Coconut Neera-A Vital Health Beverage from Coconut Palms: Harvesting, Processing and Quality Analysis
}

\author{
Mohankumar Chinnamma *, Salini Bhasker, Malavika Binitha Hari, Divyaa Sreekumar and \\ Harish Madhav
}

Molecular Biology Division, SCMS Institute of Bioscience and Biotechnology Research and Development (SIBBR\&D), Management House, South Kalamassery, Cochin 682033, Kerala, India; salini.bhasker@scmsgroup.org (S.B.); malavikabh@gmail.com (M.B.H.); divyaa.sreekumar5@gmail.com (D.S.); harish@scmsgroup.org (H.M.)

* Correspondence: directorsibb@scmsgroup.org; Tel.: +91-484-255-6315

Received: 12 January 2019; Accepted: 30 January 2019; Published: 2 March 2019

\begin{abstract}
Nature has made nutritive products in such a way that it cannot be manufactured in laboratories or in mills. Coconut Neera is the natural sap of the mature coconut palms rich with all essential nutrients, minerals and vitamins for human health. Harvesting of Neera from the spadix of the palms without disturbing the physiology of the tree has a lot of potential at the industrial scale. However, the development of alcohol in the extracted sap during tapping by auto-fermentation has given a misnomer for Neera as "sweet toddy". Hence, the commercial popularity of Neera as a health drink has diminished at a global level. Though several traditional techniques like the usage of calcium hydroxide (lime) and the application of the chiller device during harvesting Neera from spadix have been practiced for collecting non-fermented Neera, none of the techniques were found acceptable at the commercial level. The results of the present study demonstrate the harvesting and processing procedure standardized for the collection and storage of non-fermented Neera from palms by repeated field trials. The cumulative effect of the anti-fermentation solution (AFS) with the presence of the two preservatives - citric acid $(5 \mathrm{mM})$ and potassium metabisulphite $(2 \mathrm{mM})$-by preventing fermentation from the level of harvesting to processing was confirmed. The zero content of alcohol in raw Neera indicates the AFS action. The proximate composition of primary constituents and the content of minerals, amino acids and vitamins present in Neera highlights its nutrient value as a health beverage. The higher content of minerals—sodium and potassium (15.2 $\mathrm{mg}$ and $100 \mathrm{mg})$, the elevated level of amino acids-cysteine $(14 \mathrm{mg})$, tyrosine $(7.11 \mathrm{mg})$, arginine $(7 \mathrm{mg})$ and the presence of vitamin C (65 mg) and vitamin A as retinol (4.88 IU)-indicates the therapeutic importance of coconut Neera. The data of oral toxicity and the glycemic index further support the vital quality.
\end{abstract}

Keywords: Cocos nucifera; coconut palms; coconut Neera; anti-fermentation solution; harvesting and processing; Neera sugar; Neera concentrate

\section{Introduction}

Coconut has been in existence for millions of years in almost all tropical countries, and the people of the tropical world use a eulogistic epithet "Tree of Life" for coconut palms. This is because whatever is needed for one's livelihood-food, fuel, medicine and shelter-is available from this wonder palm. Coconut palm has been studied mostly from the commercial angle, as it is the source of edible oil, food, coconut water, coconut milk, fibre, wood and fuel. Because of the diversified food value, the potential of coconut can be exploited from the flowering phase to the mature nut [1]. At the reproductive phase, a coconut tree develops bunches of male and female flowers that are kept inside in a protective coat 
safely, called spadix, until it blossoms for reproduction (Figure 1). The sweet sap of unblossomed mature spadix of coconut trees has been used as a natural drink for decades, but its marketing stability at the commercial scale is not at all competent due to the fermented nature of the drink, leading to the formation of alcohol. Technically, the sweet sap oozed out during tapping from the spadix has two nutritional status: (i) Fermented sap with 5-8\% alcohol called sweet toddy and (ii) non-fermented sap named Neera with zero alcohol. Though both the saps have vital nutrients, the presence of alcohol in sweet toddy remains as a hurdle for popularizing it as a natural soft drink. The major concern of the Neera industry is to maintain the nutritional quality with zero alcohol since Neera has an innate tendency of auto-fermentation. Hence, the harvesting of Neera without auto-fermentation remains as a challenge before the Neera industry. Despite the traditional approach of tapping, a scientific approach for harvesting and processing Neera by maintaining its nutritional and therapeutic value at the industrial scale has not been done properly.

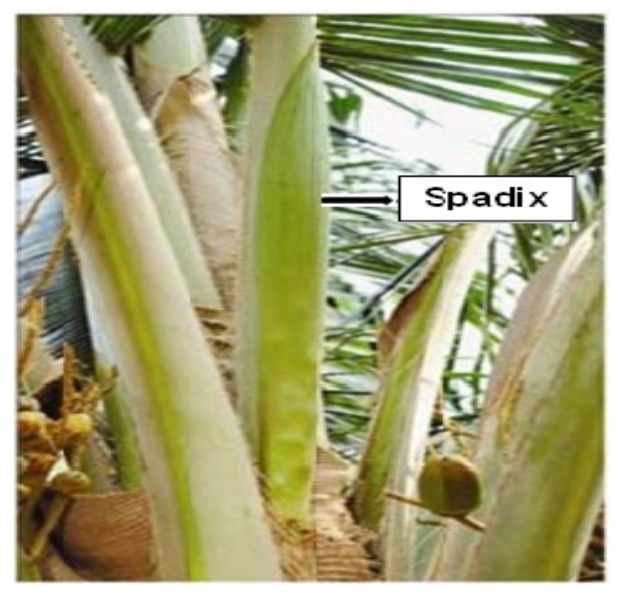

Figure 1. The unblossomed spadix of a mature coconut palm.

Generally, the tapping procedure followed for Neera production is precisely a repetition of the traditional toddy extraction, and this may be the possible reason that Neera has got the misnomer "sweet toddy" [2,3]. Therefore, the major threat in the harvesting process of Neera from the spadix of coconut palm is the natural fermentation or auto fermentation of the sap. Being a natural sugary solution extracted from the plant tissue, it has an innate tendency of getting fermented and it can happen by two means: auto-fermentation of the sap and unhygienic harvesting and storage. Fresh coconut sap (Neera) at the time of harvest is sweet in taste with all the vital nutrients of an energy health drink. However, the innate association of micro-organisms like yeast and bacteria in the sweet sap activates fermentation, resulting in the production of ethyl alcohol [4]. Therefore, the present investigation was undertaken with the aim to produce non-fermented Neera from coconut palms with the following objectives: to develop an exclusive harvesting procedure for Neera by preventing the in situ fermentation at the field itself, to design a processing protocol for the harvested Neera with a stable shelf life at room temperature and to analyze the nutritional quality of the processed Neera for determining its vital nature as a health beverage.

\section{Materials and Methods}

The methodology part of the investigation was carried out under four phases: tapping and harvesting; processing and storing the harvested Neera; conducting a nutritional analysis; preparing the value-added products from Neera. 


\subsection{Tapping and Harvesting}

A scientific approach was maintained for the harvesting by following modifications in the traditional tapping practiced by the toddy tappers (Figure 2): (i) The selection of healthy palms: As the first step of tapping, 250 healthy coconut palms (Cocos nucifera) of approximate 25-30 m with mature unblossomed spadix were selected for the study. The height of the tree, number of mature spadix and general health of the palms were taken as the criteria for selection. (ii) Surface sterilization of the palm crown: For the tapping process, traditional toddy tappers were identified and trained. Unlike the traditional tapping for getting toddy from palms, the crowns of the palms were cleaned properly by the tapper to expose the spadix for the smooth tapping. As the first step of Neera harvest, a mild disinfectant- $0.05 \%$ sodium hypochlorite-was sprayed in the crown to create an aseptic environment. (iii) Cleaning of the spadix: The identified spadix for tapping was sprayed with distilled water from the base to the top for cleaning. After washing, the surface of spadix was cleaned by tissue paper to make it dry. (iv) Beating of the spadix: The cleaned spadix was subjected to an initial beating process from the base to the top with a professional skill for 3-4 days. After the initial beating, the tip of the spadix was chopped with a sharp sterile knife-the indigenous tool of the traditional tapper. The beating process was continued for 10-15 days. Every day, the chopped end of the spadix was covered by a sterilized plastic mesh carefully after the beating. This was for preventing entry of insects and other small organisms. The beating was done twice-in morning and evening. (v) Application of the sterilized clay on the spadix: The excised end of the spadix always appeared as wet due to the exudation of Neera from the spadix during the beating process. There is every possibility of leaching of this sugary exudate to the basal part of the spadix which will damage the entire system. This can be prevented by spreading a sticky matrix on the surface of the cut end. Traditionally toddy tappers were using sticky natural clay on the surface. In the case of Neera harvesting, slight modification was made by sterilizing the clay, i.e., sterilized clay was applied on the cut end of the spadix by the tapper. The tapper should wear gloves while applying the clay so that further contamination can be avoided. The clay was sterilized by autoclaving. (vi) The collection vessel: Traditionally a clay pot was used for the collection by toddy tappers. Due to the repeated use of the pot by the tappers, for the collection, it was not properly maintained in a hygienic way. In the case of Neera harvesting, an aseptic mode was created by using a sterilized plastic vessel of $5 \mathrm{~L}$ capacity. The vessel was cleaned and sterilized prior to the insertion to the processed spadix for collecting Neera. (vii) Insertion of the sterile vessel: The vessel was inserted to the spadix after 15-20 days of beating based on the flow of Neera from the spadix. After 15-20 days, Neera was exudated from the processed spadix at a rate of 100-200 mL initially and the volume was increased to $1 \mathrm{~L}$ after one month and subsequently to $2 \mathrm{~L}$ after two months. The volume of the Neera exudate varied from palm to palm based on several factors-age, height, health of the palm and time of collection. (viii) Collection of the Neera: The vessel can be kept for collection at two times-once in the morning and the other in the evening in the same spadix. The collection vessel kept in the morning can be harvested in the evening, and the vessel kept in the evening can be harvested by the next day's morning. Therefore, an average yield of $2 \mathrm{~L} /$ palm/day can be harvested, but depending on the age and health of the palms, the volume will increase to $3-5 \mathrm{~L} / \mathrm{palm} /$ day. The Brix value of the harvested Neera was checked by using a refractometer at the plantation. 


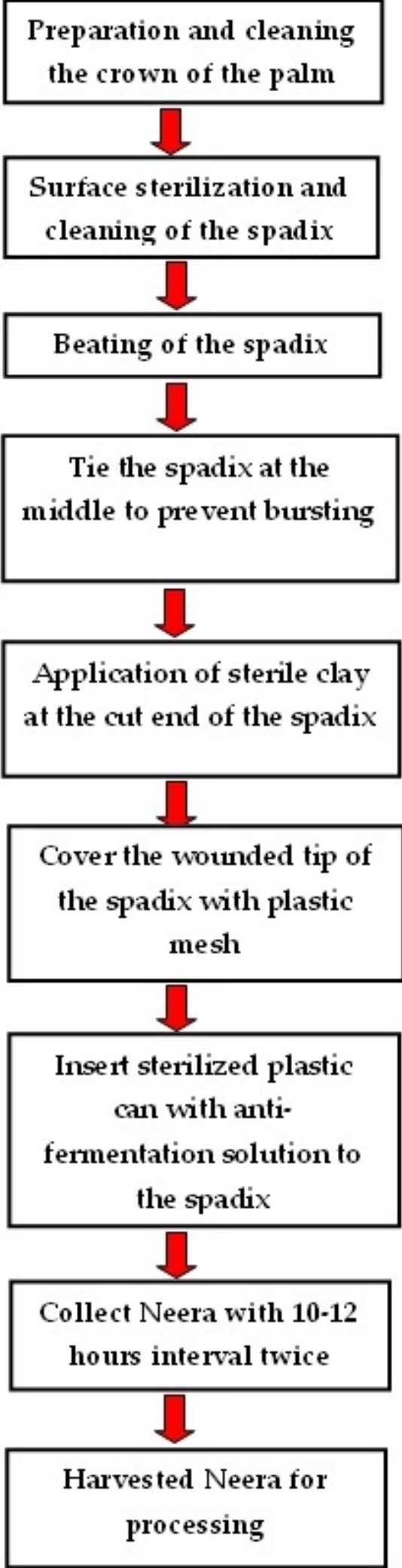

Figure 2. The modified harvesting steps of coconut Neera.

\subsection{Preparation and Usage of the Anti-Fermentation Solution (AFS)}

A new combination was prepared for suppressing the tendency of fermentation of raw Neera during harvesting with respect to its mode of action. Proper standardization was done by several 
repeated field trials for optimizing the anti-fermentation formula. Raw Neera exudated from the coconut spadix during harvesting has got the innate tendency of getting fermented. Therefore, it is essential to prevent the auto-fermentation by suppressing the growth of microbes prior to processing. An anti-fermentation solution (AFS) was prepared by the combination of two chemicals-citric acid (CA) and potassium metabisulphite (KMS) — that have been accepted as preservatives in food and natural drinks [5]. The combination of the two salts was optimized to the level of 4-5 mM for citric acid with a concentration of KMS 1.5-2.5 mM in raw Neera/L. Using the treatment of the anti-fermentation solution in the harvested Neera, yet another problem appeared that was the fermentation of raw Neera at the crown within the collection vessel during harvesting. Though traditionally the toddy tappers have been practicing the usage of calcium hydroxide (lime) in the collection vessel for collecting sweet toddy, the presence of lime remains as a health hazard. Moreover, the processing steps of removal of the lime look more tedious. Therefore, the fermentation of Neera within the collection vessel was checked by adding a concentrated volume of $10 \mathrm{~mL}$ AFS/L Neera with the same molarity $(5 \mathrm{mMCA}$ and $2 \mathrm{mM} \mathrm{KMS}$ ) to the collection vessel at the time of insertion by the tapper. Based on the volume of Neera exudate from each palm, the volume of AFS can be adjusted by the tapper.

\subsection{Processing and Storage of Harvested Neera}

The harvested Neera was filtered at the plantation itself through a cheese cloth for removing the solid debris. The filtered Neera was stored in a can and transported to the laboratory for further processing. Prior to the processing of the raw Neera, the brix value and the $\mathrm{pH}$ of the harvested Neera were checked. The processing steps include (i) Microfiltration, (ii) Pasteurization, (iii) Bottling and (iv) Storage (Figure 3).

(i) Microfiltration: The raw Neera was filtered through micro filters with a pore size of 100 microns under aseptic conditions.

(ii) Pasteurization: The filtered raw Neera was stored in a sterilized vessel for pasteurization for $10-15 \mathrm{~min}$ at a temperature range of $75-85^{\circ} \mathrm{C}$. A mild agitation was inevitable during pasteurization. The temperature was kept constant at $80^{\circ} \mathrm{C}$ during pasteurization by remote control.

(iii) Bottling: The pasteurized Neera was bottled by an automatic bottling machine with a volume $(200 \mathrm{~mL})$ in polypropylene (PP) bottles and $300 \mathrm{~mL}$ in glass bottles and capped and sealed automatically. The entire steps were done in a closed system for avoiding further contamination during processing.

(iv) Storage: Shelf life was checked periodically by analyzing the $\mathrm{pH}$, brix value and nutritional components.

\subsection{Quality Analysis of Neera}

As the first part of the analysis, the Neera was subjected to the quantification of the microbial load at three levels: (a) Raw Neera at the time of harvest, (b) processed Neera and (c) processed Neera after 3 months of storage. The total fungal count was estimated by following the protocol of the Indian Standard: 5403 test method [6]. A yeast extract-dextrose-chloramphenicol-agar medium was prepared, and pour plates were made using the raw, processed and stored Neera samples at different dilutions. The plates were then incubated at $25 \pm 1{ }^{\circ} \mathrm{C}$ for 3 days. A control plate was also maintained. The total bacterial count was detected following the IS: 5402 test method. The yeast extract-glucose-casein agar medium pour plates were prepared using the raw, processed and stored Neera samples at different dilutions. They were incubated at $30 \pm 1{ }^{\circ} \mathrm{C}$ for $72 \mathrm{~h}$. A control plate was also maintained [7]. 


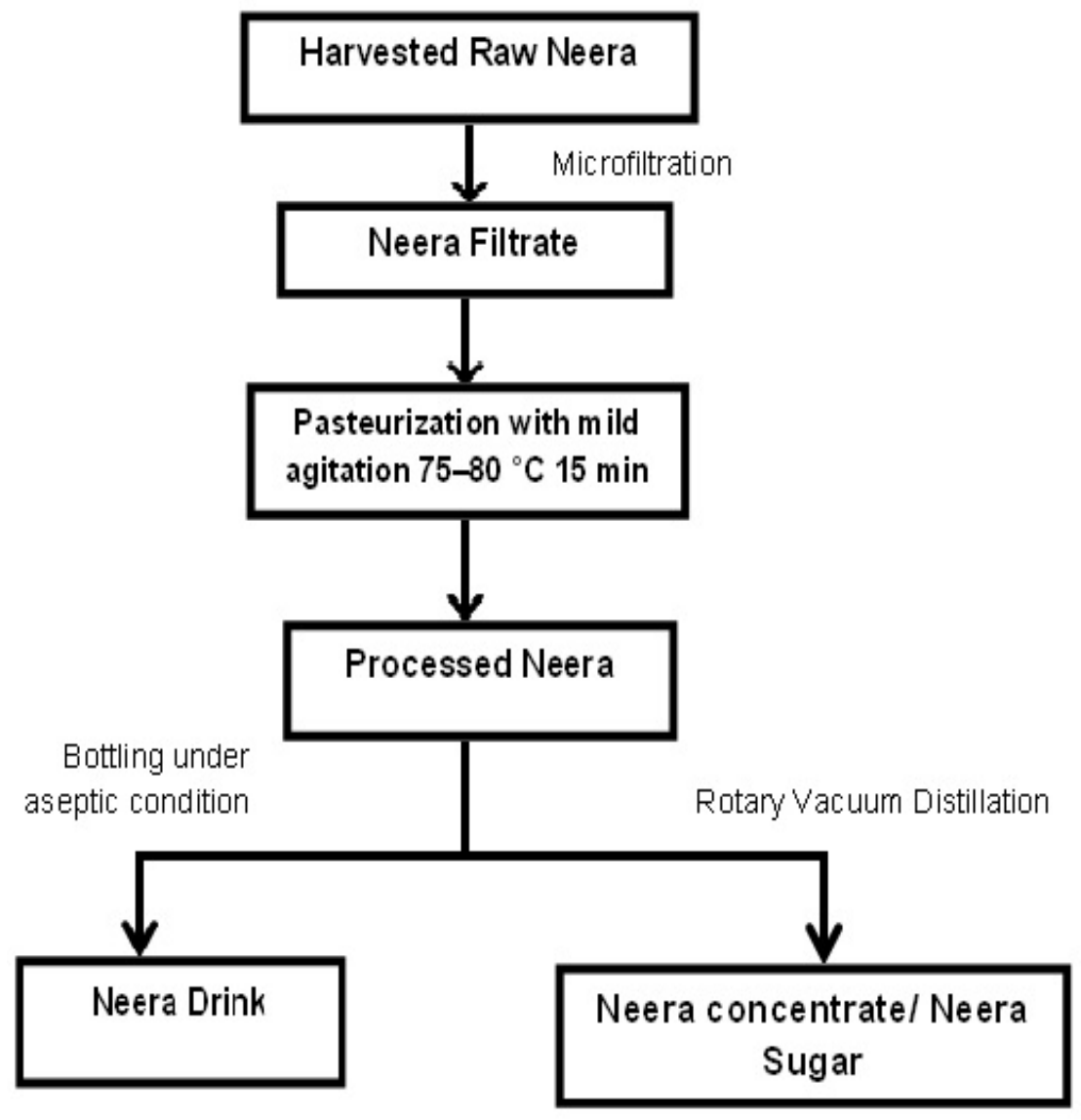

Figure 3. The processing of raw coconut Neera.

\subsection{Estimation of Alcohol Content}

The presences of ethyl alcohol in traditional Neera, Neera with AFS, processed Neera and Neera after storage were measured. The estimation was done colorimetrically using a sodium dichromate-sulphuric acid mix [8]. A standard graph of the ethanol content was prepared by taking an aliquot of stock solution at different concentrations. In the experimental part, an aliquot of Neera was taken, and the reaction was done by adding the reaction mixture consisting of sodium di chromate, sodium acetate buffer ( $\mathrm{pH} 4.3$ ) and $1 \mathrm{~N} \mathrm{H}_{2} \mathrm{SO}_{4}$ in the ratio 1:1:5. The control experiment was done by taking water instead of Neera in the reaction mix. The experiment and the control were incubated for $45 \mathrm{~min}$ after a vigorous shake for $1 \mathrm{~min}$. The optical density was measured at $578 \mathrm{~nm}$.

\subsection{Estimation of Vital Nutrients}

For determining the nutritive value of Neera as a health beverage, the level of primary nutrients was quantified by following the standard protocols [9-13]. Lipid profile: The lipid profile was analyzed by the gas chromatographic technique to determine the presence of unsaturated and saturated fatty acids [14,15]. Total carbohydrates (TC): The estimation of TC in Neera was done by following the Morris-Anthrone method with a modification in the sample preparation method so that it can be adapted to use on food [16,17]. A $10 \mathrm{~mL}$ anthrone reagent was added to $5 \mathrm{~mL}$ of sample Neera. The solution was mixed and allowed to stand for $10 \mathrm{~min}$. The colour developed was measured at $540 \mathrm{~nm}$ in a spectrophotometer. A blank containing distilled water and standards containing 1-6 mg glucose/100 $\mathrm{mL}$ of solution were run parallel [18]. A sugar profile analysis was done to determine the presence of monosaccharides and disaccharides using high performance liquid chromatography-refractive index detector (HPLC-RID) [19]. Mineral content: The mineral content in Neera was analyzed using inductively coupled plasma mass spectrometry (ICPMS) and 
atomic absorption spectrometry by following the guidelines in the manual of methods of analysis of foods: metals [20]. Amino acid profile: The essential amino acids present in Neera were identified and analyzed using liquid chromatography [21,22]. Vitamins: The vitamins present in Neera were determined using the liquid chromatographic technique following the test methods elaborated in the first edition of vitamin analysis for the health and food sciences [23].

\subsection{Oral Toxicity Test and Glycemic Index of Processed Neera}

An oral toxicity test was done for processed Neera to detect the toxicity level. The extract was administered at $5000 \mathrm{mg} / \mathrm{kg}$ to female Albino Wistar rats as the starting dose, and dosing of further animals for additional test dose levels was based on the 48-h survival pattern of previously dosed animals up to that time. On the day of dosing, the animal was observed for mortality and clinical signs for first $10 \mathrm{~min}, 30 \mathrm{~min}, 1 \mathrm{~h}, 2 \mathrm{~h}, 4 \mathrm{~h}$ and $6 \mathrm{~h}$ after dosing and thereafter once a day for 14 days. The body weights of the rats were recorded, and the weekly body weight gains were calculated. After 14 days of observation, all surviving animals were sacrificed and subjected to complete necropsy. This study was performed as per the Organisation for Economic Co-operation and development OECD guideline for the testing of chemicals [24].

The glycemic index of Neera was evaluated using the Dextrose from HiMedia and the glucose assay kit from Merck India Private Limited, Mumbai. Six rats were allotted to two groups, three in each. Group I served as the glucose control (dextrose prepared as $1 \mathrm{~g} / \mathrm{kg}$ rat body weight). Group II served as the test group (Neera concentration; $1 \mathrm{~mL} / \mathrm{kg}$ rat body weight). The animals were fasted for $12 \mathrm{~h}$ prior to test substance administration but had free access to water. The glucose levels were estimated using the glucose assay kit at various time intervals ( 0 min before the test substance administration and 15, 30, 45, 60, 90 and $120 \mathrm{~min}$ after the test substance administration). The data were analyzed to get an incremental area under curve (IAUC), and the glycemic index was calculated using following formula: (IAUC of the Neera/IAUC of the glucose) $\times 100$.

\subsection{Production of Value-Added Products}

The development of value-added products from the processed Neera has a lot of industrial value in the food industry at a global level. Hence, two value-added products were developed using the processed Neera.

(i) Neera Concentrate: Neera concentrate—commercially called Neera squash-was developed by concentrating the Neera drink from a brix value 14 to $45-50$ using rotary vacuum distillation under controlled temperatures.

(ii) Neera Sugar: The process of making Neera sugar was similar to that of the Neera concentrate. At the level of getting the Neera concentrate of a brix value 45-50, it was again subjected to further vacuum distillation process until the brix value came to the level of 55-60 with a texture of a semisolid form. This semisolid Neera thick concentrate was transferred to a wide metal pan and kept in an incubator at $70{ }^{\circ} \mathrm{C}$ for overnight. After proper dehydration, the solidified Neera as white a Neera sugar was powdered in a blender and bottled.

\subsection{Statistical Analysis}

For the quality analysis of the sample, a statistical analysis was done to detect the means and standard deviations of both raw and processed Neera samples. Since, the duration of the study was for 2 years, the samples were selected at three months interval ( 90 days). Therefore, the quality analysis for 8 batches was done. The selection of 90 days was in order to check the shelf life. 


\section{Results}

\subsection{Tapping and Harvesting}

Figure 2 demonstrates the modified tapping procedure of non-fermented Neera by using AFS during harvesting. Proper training was given to tappers for following all the modifications that were incorporated from the traditional tapping. From the initial level of the selection of healthy palms up to the final phase of collection of Neera, proper care was given in the addition of AFS, i.e., $10 \mathrm{~mL} / \mathrm{L}$ Neera to the collection vessel before inserting to the cut end of the spadix.

\subsection{Anti-Fermentation Solution: Mode of Action of AFS}

A cumulative action was seen by CA and KMS in AFS. During the harvesting of Neera, CA lowers the $\mathrm{pH}$ of raw Neera to acidic level. In the acidic condition, KMS exhibits the property of suppressing the growth of bacteria and fungi in the harvested Neera, thereby preventing auto-fermentation. Since both CA and KMS are accepted food preservatives, it will be fully secure and will not make any biosafety issues during usage.

\subsection{Processing and Bottling of Neera}

The brix value of harvested Neera was found between 14 and 16, and the $\mathrm{pH}$ was at the range of 5.2-5.7. Figure 3 shows the processing steps of the harvested Neera. The raw Neera with AFS was carried to the Neera plant for further processing. As the first step, the raw Neera was micro-filtered to remove the impurities, and the filtrate was pasteurized with mild agitation at $75-80{ }^{\circ} \mathrm{C}$ for $10-15 \mathrm{~min}$. The processed Neera was bottled under aseptic conditions either manually in a laminar hood or using an automatic filling device. The processed Neera was also used for making the value-added products like Neera sugars and concentrates. Periodic analysing of the $\mathrm{pH}$, brix value, protein, sugar, minerals, amino acids and vitamins revealed that processed Neera can be kept at room temperature for more than 90 days without any quality change. Figure 4 displays the pasteurized Neera filled in glass bottles of $300 \mathrm{~mL}$ capacity.

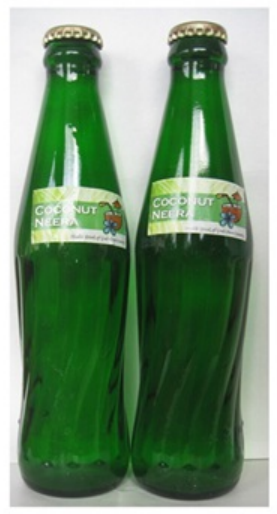

(a)

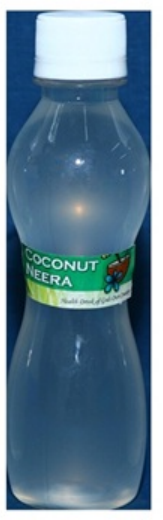

(b)

Figure 4. Bottled pasteurized coconut Neera: (a) Neera filled in glass bottles of $300 \mathrm{~mL}$ capacity and (b) Neera filled in polypropylene (PP) bottles of $200 \mathrm{~mL}$ capacity.

\subsection{Microbial Load of Raw and Processed Neera}

The microbial load of raw Neera collected by traditional tapping was checked along with the processed Neera. Table 1 details the bacterial and fungal count as colony forming units (CFU) per $\mathrm{mL}$ in raw Neera with and without AFS. A rich load of bacterial count was observed in raw Neera, but the fungal count was negligible. In raw Neera with AFS, the bacterial count has shown a drastic depletion to the level of $10 \mathrm{CFU} / \mathrm{mL}$ from 102,000 CFU, which strongly indicates the successful effect of AFS. Moreover, the limited level of microbial load in raw Neera with AFS provides a strong indication of 
the hygienic environment induced by the effect of the modifications during tapping and collection. The bacterial count of processed Neera after three months of storage was checked. No increase was observed in the bacterial count from the level of $10 \mathrm{CFU} / \mathrm{mL}$ as noticed in raw Neera with AFS. From the high rate of bacterial count in raw Neera at the time of harvest, it is advisable that raw Neera cannot be recommended as a drink without pasteurization. As per the international food standards the bacterial count $(\mathrm{CFU} / \mathrm{mL}$ ) was limited to a range of 100-1000 CFU for health drinks.

Table 1. The microbial load of raw coconut Neera with and without AFS.

\begin{tabular}{ccc}
\hline Organism & Raw Neera without AFS & Raw Neera with AFS \\
\hline Total Bacterial Count $/ \mathrm{mL}(\mathrm{CFU} / \mathrm{mL})$ & 102,000 & Less than $10 \mathrm{CFU}$ \\
Total Fungal Count $/ \mathrm{mL}(\mathrm{CFU} / \mathrm{mL})$ & Less than $10 \mathrm{CFU}$ & Less than $10 \mathrm{CFU}$ \\
\hline
\end{tabular}

\subsection{Alcohol Content}

As an undesirable component of Neera by traditional harvesting, the content of alcohol in the modified harvesting method, i.e., Neera with AFS, was checked at each level. The value was compared to the Neera harvested by traditional tapping. Figure 5 demonstrates the alcohol content of Neera harvested traditionally, Neera collected in chiller device after tapping and the Neera with AFS. It is obvious that traditional Neera as well as chilled Neera showed the presence of alcohol. The Neera with AFS showed zero level of alcohol.

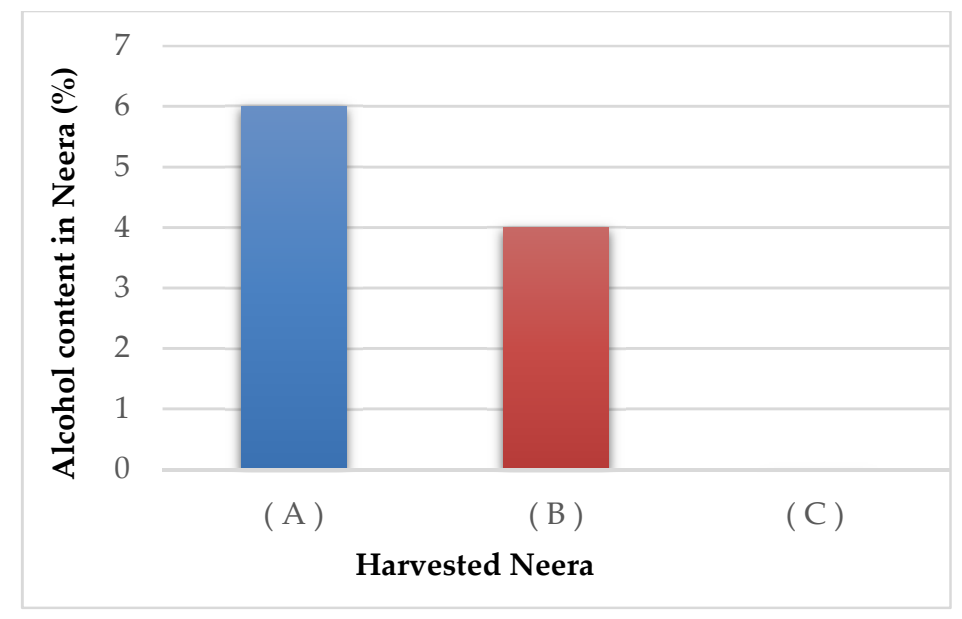

Figure 5. The percentage of alcohol content in coconut Neera. (A) Neera harvested traditionally; (B) Neera collected in chiller device after tapping; and (C) Neera with AFS.

\subsection{Nutritional Composition of Processed Neera}

The processed Neera was analysed at the macro and micro levels for determining the nutritional quality. Table 2 displays the level of primary nutrients like proteins, fats and carbohydrates and the food calorie of Neera. The data highlights the nutritive value of Neera as an energy drink for infants, youth and old people. The lipid profile demonstrates the presence of unsaturated and saturated fatty acids more or less in the same ratio at a minimum level (Table 2). Though the value of lipid constituents look negligible, the combination of unsaturated and saturated lipids showed an equal ratio of 1:1. The HPLC profile of total sugars shows the presence of three major sugars: glucose, sucrose and fructose. The fractions like arabinose, rhamnose, xylose, ribose, mannose and galactose were not found in Neera (Table 3). The Neera drink, as such, has a good combination of all the essential minerals with rich content of potassium, sodium, magnesium, calcium and iron. Table 3 exhibits the mineral content of Neera drink. The mineral content of Neera supports both the nutritive value of Neera and the therapeutic relevance of the drink towards mineral deficiency. The amino acid profile of 
Neera showed content of all the essential amino acids needed to human system (Table 4). The higher content of arginine, cysteine and tyrosine indicate the need of using Neera by infants and growing children $[25,26]$. It is significant to note that the Neera drink is rich in vitamin $C$ and the presence of Vitamin A as retinol and vitamin B2, B3 and B6 provides additional food values to Neera (Table 4).

Table 2. The proximate composition and lipid profile of processed coconut Neera.

\begin{tabular}{cccc}
\hline & Components & Quantity/100 mL & S.D. Mean \\
\hline \multirow{3}{*}{ Proximate composition } & Food Energy & $74.86 \mathrm{Kcal}$ & 0.51 \\
& Protein & $0.28 \mathrm{~g}$ & 0.004 \\
& Carbohydrates & $18.03 \mathrm{~g}$ & 0.03 \\
Fats & $0.18 \mathrm{~g}$ & 0.006 \\
\hline \multirow{2}{*}{ Lipids } & Unsaturated fatty acids & $80 \mathrm{mg}$ & 0.10 \\
& (Oleic \& Linoleic acids) & Cholesterol & $100 \mathrm{mg}$ \\
& Saturated fatty acids & NIL & 0.47 \\
\hline
\end{tabular}

Table 3. The sugar profile and mineral composition of coconut Neera.

\begin{tabular}{cccc}
\hline & Components & Quantity/100 $\mathbf{~ m L}$ & S.D. Mean \\
\hline \multirow{4}{*}{ Sugars } & Glucose & $1.5 \mathrm{~g}$ & 0.02 \\
& Fructose & $0.6 \mathrm{~g}$ & 0.02 \\
& Sucrose & $13.4 \mathrm{~g}$ & 0.41 \\
\hline \multirow{4}{*}{ Minerals } & Sodium & $15.2 \mathrm{mg}$ & 0.05 \\
& Potassium & $100 \mathrm{mg}$ & 0.47 \\
& Iron & $0.36 \mathrm{mg}$ & 0.003 \\
& Zinc & $40 \mu \mathrm{g}$ & 0.11 \\
& Magnesium & $6 \mathrm{mg}$ & 0.01 \\
& Calcium & $1.8 \mathrm{mg}$ & 0.04 \\
& Manganese & $10 \mu \mathrm{g}$ & 0.04 \\
& Selenium & $10 \mu \mathrm{g}$ & 0.07 \\
& Copper & $27 \mu \mathrm{g}$ & 0.06 \\
\hline
\end{tabular}

Table 4. The amino acid profile and vitamin content of coconut Neera.

\begin{tabular}{|c|c|c|c|}
\hline & Components & Quantity/100 mL & S.D. Mean \\
\hline \multirow{11}{*}{ Amino acids } & Aspartic acid & $4 \mathrm{mg}$ & 0.08 \\
\hline & Valine & $2.19 \mathrm{mg}$ & 0.09 \\
\hline & Threonine & $3.95 \mathrm{mg}$ & 0.07 \\
\hline & Alanine & $2.78 \mathrm{mg}$ & 0.12 \\
\hline & Methionine & $12 \mathrm{mg}$ & 0.66 \\
\hline & Leucine & $0.47 \mathrm{mg}$ & 0.008 \\
\hline & Isoleucine & $2.19 \mathrm{mg}$ & 0.02 \\
\hline & Histidine & $99.6 \mathrm{mg}$ & 0.42 \\
\hline & Cysteine & $14 \mathrm{mg}$ & 0.13 \\
\hline & Arginine & $7 \mathrm{mg}$ & 0.14 \\
\hline & Tyrosine & $7.11 \mathrm{mg}$ & 0.18 \\
\hline \multirow{5}{*}{ Vitamins } & Vitamin B2 & $15.4 \mu \mathrm{g}$ & 0.51 \\
\hline & Vitamin B3 & $210 \mu \mathrm{g}$ & 0.78 \\
\hline & Vitamin B6 & $30 \mu \mathrm{g}$ & 0.56 \\
\hline & Vitamin C & $65 \mathrm{mg}$ & 0.77 \\
\hline & $\begin{array}{l}\text { Vitamin A (As retinol) (One IU Vitamin } \\
\text { A is equivalent to } 0.3 \mu \mathrm{g} \text { of retinol) }\end{array}$ & $4.88 \mathrm{IU}$ & 0.15 \\
\hline
\end{tabular}




\subsection{Acute Oral Toxicity Data of the Neera Drink}

The rats treated at $5000 \mathrm{mg} / \mathrm{kg}$ of the Neera extract survived throughout the study period. The treated rats exhibited no clinical signs following dosing and up to $6 \mathrm{~h}$ post treatment. The overall body weight gain was found to be normal at the end of 14-day observation period. No major gross pathological changes were observed in the treated rats. Based on the findings of the present study, the median lethal dose of Neera after single oral administration in female Albino Wistar rats was found to be more than $5000 \mathrm{mg} / \mathrm{kg}$ body weight. Hence the product was found absolutely non-toxic. Animals treated at the dose level of $5000 \mathrm{mg} / \mathrm{kg}$ body weight survived throughout the study period. These animals did not show any abnormal clinical signs following dosing and during the observation period of 14 days. The overall body weight gain of rat treated with $5000 \mathrm{mg} / \mathrm{kg}$ was found to be normal at the end of 14-day observation period. The treated animals exhibited normal weight gain during the study period. Macroscopic examination of the animals sacrificed at termination revealed no abnormalities. Histopathological examination was not conducted since no major gross pathological abnormalities were observed on necropsy.

\subsection{Glycemic Index of Neera}

The data was analyzed to get an incremental area under curve (IAUC), and a glycemic index was calculated using the formula: (IAUC of the Neera/IAUC of the glucose) $\times 100$. Table 5 demonstrates the level of serum glucose at different time intervals in the presence of glucose and Neera. Table 6 demonstrates the mean of Incremental Area under Curve (IAUC). The glycemic index of the Neera was found to be 52.17. The lower levels of glycemic index favors its consumption for diabetic patients, but a more exhaustive therapeutic analysis is essential to substantiate the hypothesis.

Table 5. The mean values of serum glucose $(\mathrm{mmol} / \mathrm{L})$ in Albino Wistar rats treated with Glucose

( $1 \mathrm{~g} / \mathrm{kg}$ rat body weight) and Neera $(1 \mathrm{~mL} / \mathrm{kg}$ rat body weight) over a time period of $0-120 \mathrm{~min}$.

\begin{tabular}{|c|c|c|c|c|c|c|c|c|}
\hline \multirow{2}{*}{ Groups } & \multicolumn{8}{|c|}{ Serum Glucose $(\mathrm{mmol} / \mathrm{L})$} \\
\hline & & $\mathrm{O} \min$ & $15 \mathrm{~min}$ & $30 \mathrm{~min}$ & $45 \mathrm{~min}$ & $60 \mathrm{~min}$ & $90 \mathrm{~min}$ & $120 \mathrm{~min}$ \\
\hline \multirow{3}{*}{$\begin{array}{l}\text { Glucose }(1 \mathrm{~g} / \mathrm{Kg} \\
\text { rat b.w. }\end{array}$} & Mean & 4.00 & 9.91 & 9.43 & 9.19 & 8.72 & 7.50 & 6.28 \\
\hline & S.D. & 0.20 & 0.41 & 1.58 & 0.58 & 0.41 & 0.39 & 0.52 \\
\hline & S.E.M. & 0.11 & 0.24 & 0.91 & 0.33 & 0.23 & 0.23 & 0.30 \\
\hline \multirow{3}{*}{$\begin{array}{c}\text { Neera }(1 \mathrm{~mL} / \mathrm{Kg} \\
\text { rat b.w.) }\end{array}$} & Mean & 4.03 & 4.41 & 4.37 & 4.37 & 4.25 & 4.08 & 4.13 \\
\hline & S.D. & 0.29 & 0.36 & 0.30 & 0.26 & 0.27 & 0.35 & 0.24 \\
\hline & S.E.M. & 0.17 & 0.21 & 0.17 & 0.15 & 0.15 & 0.20 & 0.14 \\
\hline
\end{tabular}

Table 6. The mean IAUC with standard deviation of Glucose $(1 \mathrm{~g} / \mathrm{kg}$ rat body weight) and Neera $(1 \mathrm{~mL} / \mathrm{kg}$ rat body weight)-treated Albino Wistar rats.

\begin{tabular}{ccc}
\hline Groups & & Increment Area under Curve \\
\hline Glucose & Mean & 973.25 \\
$(1 \mathrm{~g} /$ Kg rat b.w $)$ & S.D. & 46.00 \\
& S.E.M. & 26.57 \\
\hline \multirow{2}{*}{ Neera } & Mean & 507.76 \\
$(1 \mathrm{~mL} / \mathrm{kg}$ rat b.w $)$ & S.D. & 35.08 \\
& S.E.M. & 20.26 \\
\hline
\end{tabular}

\subsection{Value-Added Products}

Neera concentrate: As a natural drink with $80 \%$ water and all primary and essential nutritional constituents, one litre of Neera can be concentrated to $200 \mathrm{~mL}$ to make it a concentrate (Figure 6). Based on the texture of the Neera concentrate, it can be diluted to prepare a natural Neera drink by 
dissolving it in water without adding sugar. The Neera concentrate can be used as a bread spread and for making cakes, jilebi, ladoo, biscuits, bread, etc. Neera Sugar: The texture of Neera sugar was similar to cane sugar with a white colour (Figure 7). However, the nutritional potential of Neera sugar is not at all comparable with cane sugar since it contains all the essentials of normal human growth.

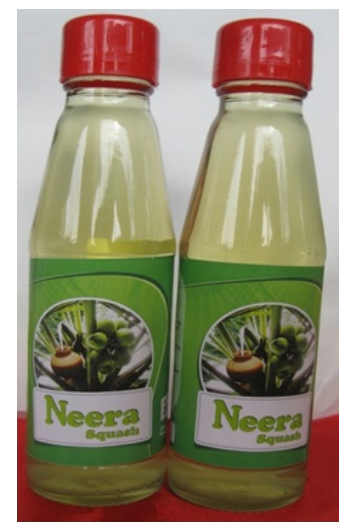

Figure 6. Coconut Neera concentrate (squash) developed from processed Neera.

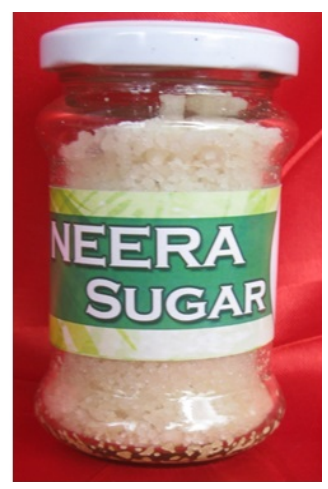

Figure 7. Coconut Neera sugar prepared from the concentrate.

\section{Conclusions}

As a unique physiological status, coconut palms can provide four natural health drinks like Tender Coconut Water, Mature Coconut Water, Coconut Neera and Sweet Toddy. Though, the coconut water and Neera exhibit varied in nutrient value, the uniqueness of sweet toddy stands on its alcohol content. Since, the quality of Neera is highly perishable due to the auto-fermentation leading to the formation of alcohol from the level of harvesting during traditional tapping, a cost-effective scientific approach is inevitable for suppressing the undesired fermentation of raw Neera. The results of the present investigation highlight the production of non-fermented Neera with a prolonged shelf life of six months at room temperature by a modified tapping protocol. A combination ratio of the preservatives-Citric Acid and Potassium Metabisulphite-worked effectively as an anti-fermentation solution for preventing the fermentation within the palm itself during harvesting. The analytical data of processed Neera confirmed it as a perfect vital health beverage compared to other natural green drinks. With respect to the mineral composition, amino acid profile and vitamin content, it would be possible to exploit this natural drink in the clinical therapy of mineral and amino acid deficiency. More studies are warranted for accepting Neera as a popular green drink at international level. Moreover, a consortium of coconut growing countries is essential for revealing the nutritional merits of this wonderful gift of coconut palms. 
Author Contributions: Conceptualization, supervision, validation and funding acquisition, M.C.; supervision, formal analysis and project administration, S.B.; methodology, investigation, data curation and writing, M.B.H.; investigation, D.S.; methodology, H.M.

Funding: This research was partially funded by the Coconut Development Board (CDB), Ministry of Agriculture and Farmers Welfare, Government of India and the SCMS Institute of Biosciences and Biotechnology Research and Development (SIBBR\&D), Cochin, Kerala, grant number F.No. 1345/2012/Tech-SCMS III.

Acknowledgments: The authors gratefully acknowledge the Coconut Development Board (CDB), Ministry of Agriculture and Farmers Welfare, Government of India for the funding of the project. We are thankful to Gopalan Unnithan Prathapachandran Nayar(Chairman) and Pramod Prathapachandran Thevannoor (Vice-Chairman) of the SCMS Group of Institutions for providing the essential infrastructure for carrying out the investigation successfully. The authors are indebted to Department of Excise, Government of Kerala, India for providing the license of tapping.

Conflicts of Interest: The authors declare no conflict of interest.

\section{References}

1. Chinnamma, M.; Bhasker, S.; Madhav, H.; Devasia, R.M.; Shashidharan, A.; Pillai, B.C.; Thevannoor, P. Production of Coconut methyl ester (CME) and glycerol from Coconut (Cocos nucifera) oil and the functional feasibility of CME as Biofuel in diesel engine. Fuel 2015, 140, 4-9. [CrossRef]

2. Ghosh, D.K.; Bandyopadhyay, A.; Das, S.; Hebbar, K.B.; Biswas, B. Coconut sap (neera)-untapped opportunity of spinoff gains in West Bengal, India. Int. J. Curr. Microbiol. App. Sci. 2018, 7, 1883-1897.

3. Siddharameswara, G.M. Coconut neera production and processing in Karnataka. Indian Coconut J. 2013, 31-33.

4. Atputharajah, J.D.; Widanapathirana, S.; Samarajeewa, U. Microbiology and biochemistry of natural fermentation of coconut palm sap. Food Microbiol. 1986, 3, 273-280. [CrossRef]

5. Abdulmumeen, H.A.; Risikat, A.N.; Sururah, A.R. Food: Its preservatives, additives and applications. Int. J. Chem. Biochem. Sci. 2012, 1, 36-47.

6. Indian Standard. Method for Yeast and Mould Count of Foodstuffs and Animal Feeds; Bureau of Indian Standard: Manak Bhawan, India, 1999; Volume 1, pp. 1-3.

7. Indian Standard. Microbiology of Food and Animal Feeding Stuffs-Horizontal Method for the Enumeration of Micro-Organisms-Colony-Count Technique at $30^{\circ} \mathrm{C}$; Bureau of Indian Standard: Manak Bhawan, India, 2012; Volume 2, pp. 1-8.

8. Sumbhate, S.; Nayak, S.; Goupale, D.; Tiwari, A.; Jadon, R.S. Colorimetric method for the estimation of ethanol in alcoholic-drinks. J. Anal. Tech. 2012, 1, 1-6.

9. Indian Standard. Method for Determination of Protein in Foods and Feeds; Bureau of Indian Standard: Manak Bhawan, India, 1973; pp. 3-10.

10. Indian Standard. Specification for Edible Groundnut Flour (Expeller Pressed); Bureau of Indian Standard: Manak Bhawan, India, 1975; Volume 1, pp. 13-14.

11. Indian Standard. Milk-Cereal Based Complementary Foods—Specification; Bureau of Indian Standard: Manak Bhawan, India, 2007; Volume 4, pp. 1-6.

12. Miller, D.S.; Payne, P.R. A ballistic bomb calorimeter. Br. J. Nutr. 1959, 13, 501-508. [CrossRef] [PubMed]

13. Charrondiere, U.R.; Chevassus-Agnes, S.; Marroni, S.; Burlingame, B. Impact of different macronutrient definitions and energy conversion factors on energy supply estimations. J. Food Comp. Anal. 2004, 17, 339-360. [CrossRef]

14. Fat (Total, Saturated and Unsaturated) in Foods, hydrolytic extraction gas chromatographic method. In AOAC Official Method 996.06, 18th ed.; AOAC International: Arlington, TX, USA, 2001.

15. Kaneda, T.; Nakajima, A.; Fujimoto, K.; Kobayashi, T.; Kiriyama, S.; Ebihara, K.; Innami, T.; Tsuji, K.; Tsuji, E.; Kinumaki, T.; et al. Quantitative analysis of cholesterol in foods by gas-liquid chromatography. J. Nutr. Sci. Vitaminol. 1980, 26, 497-505. [CrossRef] [PubMed]

16. Ludwig, T.G.; Goldberg, J.V. The anthrone method for the determination of carbohydrates in foods and in oral rinsing. J. Dent. Res. 1956, 35, 90-94. [CrossRef] [PubMed]

17. Morris, D.L. Quantitative determination of carbohydrates with dreywood's anthrone reagent. Science 1948, 107, 254-255. [CrossRef] [PubMed]

18. Dreywood, R. Qualitative test for carbohydrate material. Ind. Eng. Chem. Anal. Ed. 1946, 18, 499. [CrossRef] 
19. Ellefson, W. HPLC of mono- and disaccharides using refractive index detection. Curr. Prot. Food Anal. Chem. 2002, 6, E1.2.1-E1.2.9. [CrossRef]

20. Food Safety and Standards Authority of India. Manual of Methods of Analysis of Foods Metals; Fssai, Ministry of Health and Family Welfare: New Delhi, India, 2016; pp. 3-82.

21. White, J.A.; Hart, R.T. Derivatization Methods for Liquid Chromatographic Separation of Amino Acid in Food Analysis; Marcel Dekker, Inc.: New York, NY, USA, 1992; pp. 53-74.

22. Nollet, L.M.L. Handbook of Food Analysis: Physical Characterization and Nutrient Analysis; Marcel Dekker, Inc.: New York, NY, USA, 2004; Volume 1, pp. 83-110.

23. Eitenmiller, R.R.; Landen, W.O., Jr. Vitamin Analysis for the Health and Food Sciences; CRC Press: Boca Raton, FL, USA, 1999; pp. 3-67, 271-494.

24. OECD Guideline for the Testing of Chemicals: Acute Oral Toxicity-Up-and-down Procedure. No. 420, Section 4: Health Effects. Available online: https:/ /ntp.niehs.nih.gov/iccvam/suppdocs/feddocs/oecd/ oecd_g1420.pdf (accessed on 17 December 2001).

25. Rigo, J.; Ziegler, E.E. (Eds.) Protein and energy requirements in infancy and childhood. In Nestlé Nutr Workshop Ser Pediatr Program; Nestlé Nutrition Institute: Vevey, Switzerland, 2006; Volume 58, pp. 109-119.

26. Imura, K.; Okada, A. Amino Acid Metabolism in Pediatric Patients-Review. Nutrient 1998, 14, $143-148$. [CrossRef]

(C) 2019 by the authors. Licensee MDPI, Basel, Switzerland. This article is an open access article distributed under the terms and conditions of the Creative Commons Attribution (CC BY) license (http://creativecommons.org/licenses/by/4.0/). 